\title{
The Analysis of Cultural Communication and Regression of Wushu Association
}

\author{
Qiu-ping ZHANG \\ ${ }^{1}$ Wushu Department, Chengdu Sport Institute, Chengdu, China \\ a1046408357@qq.com \\ a Author: Zhang Qiu ping
}

Key words: mass sports; Wushu Association; cultural communication

\begin{abstract}
From the development of Wushu Association in Song Dynasty and the spread of Wushu culture, with the changes of social environment influence to the martial arts community as the starting point, through the corporate culture, weakening the single mode of communication, cultural heritage and living environment is blocked in four dimensions of analysis of the development trend of contemporary Wushu Association and trend. Research shows that the martial arts association in martial arts is the source of this, agglomeration of martial arts enthusiasts, in order to promote the development of Wushu sports, promote the popularization of Wushu culture, promote martial arts standardization and mass development of mass sports organizations. But now most of the martial arts association in the development process of the weakening of grotesque phenomenon of Wushu culture, and presents the social foundation is not solid, the duality of the government and the people "phenomenon, which caused deeply on the return of Wushu Culture in the community.
\end{abstract}

\section{The Organization of Wushu Association in Song Dynasty}

In the history of the development of Wushu, Wushu Association has an indelible effect on the spread of Wushu culture. Relatively stable social environment to promote the prosperity of the Song Dynasty City, people's attention to the entertainment gradually increased, and then the birth of a number of urban martial arts association. Jiao agency,Jinbiao agency and Yinglve agency as a city group closely associated with the martial arts, on the one hand, it enriches people's leisure life, on the other hand it also constructs a cognitive framework of Wushu for people. At the same time, there are some rural Association organizations, but they are different in nature. Among them, the City Association to improve and training skills for the purpose of. But some association is to form the rich people like idlers for entertainment purposes, these associations in skill level is not high. The Village Association in self-defense uprising, prevent foreign invasion as the main objective. Rural organizations are mainly divided into two categories, one for the voluntary association, mainly people spontaneously unite together, to carry out the activities of martial arts; the two is the establishment of government militia Association, countries in order to ensure the safety of the border, to recruit large numbers of militia, the system of training. The encouragement and support of martial arts in the Song Dynasty is one of the important factors to promote the development of rural association.

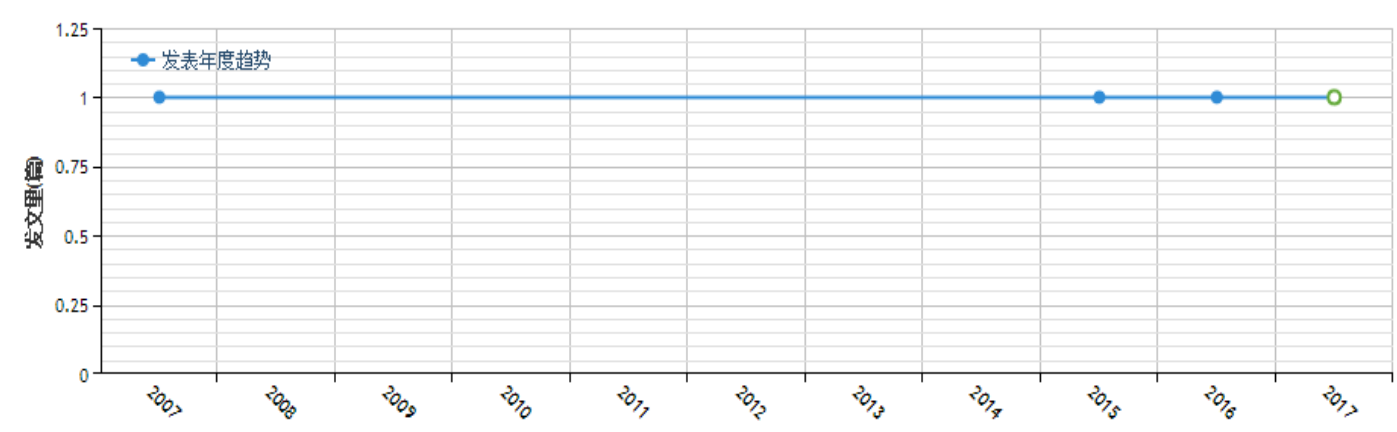

Figure 1 On the Song Dynasty martial arts research papers issued statistics nearly ten years

Take a look at Figure 1 shows in recent years, the development of martial arts, the relevant 
research, the Song Dynasty martial arts related research in a relatively blank state, American communication scholar Devre once said, "due to the spread of civilization, and is closely related to the spread of civilization and information in the form of the way, and the mode of information dissemination depends on the corresponding media, so the media is an important decision to form a civilized form factor". ${ }^{[1]}$ The Song Dynasty Martial Arts Association organized by the special media is the continuation, dissemination of martial arts skills in oral education, practitioners and other members or agency head communicate mainly through language, showing the main body, seldom used books, pen and paper etc. Oral media often can directly reflect the characteristics of the intimacy, the specific performance of it can make people in suitable environment, easy to reach a consensus or unity. However, there are some defects, when the captured information is received, and the information is not captured will disappear, never recover. This kind of instantaneous characteristic, enables the martial arts technology or its related culture in the dissemination process, cannot guarantee its information accuracy and the integrity, has certain insufficiency.

\section{Contemporary Wushu Association}

In the background of the planned economy, the rise of the different nature of the martial arts community, the relationship between the staggered. In order to clarify the complex relationship, some departments participate in the management, set up a special management mechanism at different levels, through administrative means to participate in sports management. Its advantage is that it can concentrate its limited resources to play its greatest role and achieve the desired purpose. At the same time, there are also some limitations - the social participation and support of martial arts to shut the door, so that the function of the martial arts community is difficult to fully play out. The main reason for this phenomenon is that the relevant departments of the overall control of martial arts resources, such as martial arts talent, venue facilities, technology, information sources, etc.. On the one hand, the martial arts community produce dependence, enthusiasm gradually lose independent development, on the other hand also increased the work burden, so it will gradually weaken the team cohesion and creativity. Moreover, the folk and the relevant departments have different expectations of the martial arts community, then lead to the management and service of the two sides of the dislocation, which led to the phenomenon of the "official and the people" of the retention and diffusion.

This paper takes Chengdu city of Sichuan University, Sichuan Normal University, Chengdu Sport University and other part of martial arts community groups of students were interviewed and develop a questionnaire survey, a total of 210 questionnaires were issued, the student population 190, experts 20 questionnaires, 203 were recovered, the recovery rate is $97 \%$, according to the survey of organization knowledge the removal, 7 invalid questionnaires, 93\% valid questionnaires.

Table 1 The survey table to people joined the cause

\begin{tabular}{|c|c|c|}
\hline & Number of People & Percentage(\%) \\
\hline Environmental Factors & 33 & 18 \\
\hline Technical Factors & 98 & 50 \\
\hline Cultural Factors & 65 & 32 \\
\hline Total & 196 & 100 \\
\hline
\end{tabular}

Through the data analysis, $18 \%$ of the students think they join the martial arts association is with the martial arts community school in the community every week, regularly carry out some activities, but also through peer students learn a lot about the information society, decided to apply to join the martial arts community; technical backbone of a professor of community members therefore have action. Nearly half of the students to learn; $32 \%$ students is to understand and learn more about the culture of traditional martial arts related choice of Wushu Association, to sum up, as the important media of Wushu Association, spread and inheritance of Wushu culture played a role can not be ignored.

In the process of cultural inheritance and communication, sports associations have the function of "bridging", linking "knowledge" and "receiver" together to complete the central work. 
"Technology is cultural," ${ }^{[2]}$ Community should also be combined use of mass media in the teaching of technology, change the past simple technical means of communication, culture will be removed, cut off the return to the technology to make the "shape" and "spirit" fit, enrich the body dry technology, correction of misunderstanding of the martial arts "". With the help of the martial arts community platform, through the media to the public art of communication and culture at the same time, other societies (such as Taekwondo Club) will also follow the way of conveying information more easily understandable and acceptable to the public. Every kind of communication mode has its reason to exist, but at different stages of development it plays a different role, such as decision makers, should be combined with the different social environment, different measures, enables the public to lock the "martial arts community" in the complex information network, receive and absorb relevant information. In this way, it can also make Wushu associations gradually out of the "official and civilian double lane", showing its unique social function.

\section{Summary}

In a word, the essence of Wushu Association is not a show on the contrary, with no reality whatever, its significance is that through some practical ways, to the public to "sell" the martial arts skills and the cultural connotation, change from the civilian to the officials of the martial arts "misunderstanding", "form", "God" and popular martial arts. So as to promote the development of martial arts association to become one of the important platform for the dissemination of martial arts skills, heritage of martial arts culture.

\section{Reference}

[1] Wang Gang, Zhang Dazhi. The influence of the evolution of media on the development of Wushu [J]. Journal of Shanghai Institute of Physical Education, 2007,31(2): 34-36.

[2] Chen Zhenyong. On the development of contemporary Wushu in the context of culture and vision [J]. Chinese Wushu research, 2011,1 (1): 10. 